Published in final edited form as:

Child Youth Care Forum. 2017 June ; 46(3): 395-412. doi:10.1007/s10566-016-9381-y.

\title{
Social Interpretation Bias in Children and Adolescents with Anxiety Disorders: Psychometric Examination of the Self-report of Ambiguous Social Situations for Youth (SASSY) Scale
}

\author{
Araceli Gonzalez ${ }^{1}$, Michelle Rozenman ${ }^{2}$, Audra K. Langley², Philip C. Kendall ${ }^{3}$, Golda S. \\ Ginsburg $^{4}$, Scott Compton ${ }^{5}$, John T. Walkup ${ }^{6}$, Boris Birmaher ${ }^{7}$, Anne Marie Albano ${ }^{8}$, and \\ John Piacentini ${ }^{2}$ \\ ${ }^{1}$ California State University, Long Beach, Department of Psychology \\ 2University of California, Los Angeles Semel Institute for Neuroscience and Human Behavior, \\ Division of Child and Adolescent Psychiatry \\ ${ }^{3}$ Temple University, Department of Psychology \\ ${ }^{4}$ UConn Health \\ ${ }^{5}$ Duke University Medical Center, Department of Psychiatry and Biobehavioral Sciences \\ ${ }^{6}$ Weill Cornell Medical College, Division of Child and Adolescent Psychiatry \\ ${ }^{7}$ Western Psychiatric Institute and Clinics, University of Pittsburgh Medical Center \\ ${ }^{8}$ Columbia University Medical Center, Department of Psychiatry
}

\begin{abstract}
Background-Anxiety disorders are among the most common mental health problems in youth, and faulty interpretation bias has been positively linked to anxiety severity, even within anxietydisordered youth. Quick, reliable assessment of interpretation bias may be useful in identifying youth with certain types of anxiety or assessing changes on cognitive bias during intervention.
\end{abstract}

\footnotetext{
Correspondence should be addressed to: Araceli Gonzalez, Ph.D., California State University, Long Beach, Department of Psychology, 1250 Bellflower Blvd., PSY-100, Long Beach, CA, 90840-0901, Araceli.Gonzalez@csulb.edu.

Disclosure of potential conflicts of interest:

Araceli Gonzalez declares that she has no conflict of interest. Michelle Rozenman declares that she has no conflict of interest. Audra Langley declares that she has no conflict of interest. Philip Kendall declares that he has no conflict of interest. Golda Ginsburg declares that she has no conflict of interest. Scott Compton declares that he has no conflict of interest. John Walkup declares that he has no conflict of interest. Anne Marie Albano declares that she has no conflict of interest. John Piacentini declares that he has no conflict of interest.

Compliance with Ethical Standards

Ethical approval:

All procedures performed in this study involving human participants were in accordance with the ethical standards of the institutional research committee and with the 1964 Helsinki declaration and it later amendments or comparable ethical standards.

Informed consent:

Informed consent (adults/legal caregivers) and assent (youth) were obtained from all individual participants included in the study. 
Objective-This study examined the factor structure, reliability, and validity of the Self-report of Ambiguous Social Situations for Youth (SASSY) scale, a self-report measure developed to assess interpretation bias in youth.

Methods-Participants ( $\mathrm{N}=488$, age 7 to 17) met diagnostic criteria for Social Phobia, Generalized Anxiety Disorder, and/or Separation Anxiety Disorder. An exploratory factor analysis was performed on baseline data from youth participating in a large randomized clinical trial.

Results-Exploratory factor analysis yielded two factors (Accusation/Blame, Social Rejection). The SASSY full scale and Social Rejection factor demonstrated adequate internal consistency, convergent validity with social anxiety, and discriminant validity as evidenced by non-significant correlations with measures of non-social anxiety. Further, the SASSY Social Rejection factor accurately distinguished children and adolescents with Social Phobia from those with other anxiety disorders, supporting its criterion validity, and revealed sensitivity to changes with treatment. Given the relevance to youth with social phobia, pre- and post-intervention data were examined for youth social phobia to test sensitivity to treatment effects; results suggested that SASSY scores reduced for treatment responders.

Conclusions-Findings suggest the potential utility of the SASSY Social Rejection factor as a quick, reliable, and efficient way of assessing interpretation bias in anxious youth, particularly as related to social concerns, in research and clinical settings.

\section{Keywords}

Child; Anxiety; Cognitive Bias; Interpretation; Information Processing; Social Anxiety

\section{Introduction}

Anxiety disorders are the most common mental health problem in youth, with an estimated collective prevalence of $12 \%$ to $30 \%$ (e.g., Costello, Egger, \& Angold, 2005; Merikangas et al., 2010). In the last decade, increasing evidence has implicated biases in cognitive processing as a mechanism underlying anxiety (e.g., Field \& Lester, 2010; Hadwin, Garner, $\&$ Perez-Olivas, 2006; Muris \& Field, 2008). Theoretical models of cognitive processing in anxiety disorders suggest several stages of information processing at which biases may be exhibited (Crick \& Dodge, 1994; Daleiden \& Vasey, 1997; Muris \& Field, 2008). Interpretation is the second stage of information processing, and follows encoding of or attention to environmental stimuli. Interpretation involves attributing an emotionallyvalenced resolution or outcome (e.g., threatening, benign) to situational ambiguity. For example, a child with social phobia may first notice that his peers are laughing as he approaches the group (i.e.., cognitive process of attention), and then may perceive the situation as his peers laughing at him (i.e.., cognitive process of interpretation).

The interpretation bias literature is growing and indicates that anxious children and adolescents interpret more threat from ambiguity as compared to their typically-developing, non-anxious counterparts (e.g., Hadwin, Frost, French, \& Richards, 1997; Suarez \& BellDolan, 2001; Muris, Rapee, Meesters, Schouten, \& Geers, 2003). Interpretation bias has been positively linked to anxiety severity, even within anxiety-disordered youth (e.g., Rozenman, Amir, \& Weersing, 2014). These findings are especially relevant to evidence- 
based psychosocial interventions for pediatric anxiety, as a major component of cognitivebehavioral therapy (CBT) involves identifying and challenging irrational or inaccurate thoughts about the likelihood or risk of threat in the environment (Kendall, 2012), i.e., faulty interpretations of events and their outcome. Thus, an assessment of potential interpretation biases provide a better understanding of the role of cognition in maintaining youth anxiety, and may provide specific targets for cognitive restructuring within anxiety treatment. Further, instruments that assess these processes may be valuable in quantifying and measuring change in such interpretations over the course of treatment.

Measures of interpretation bias in anxious youth have potential value in research and practice settings; however, there are several current conceptual and methodological limitations in this area. First, there is little clarification on whether interpretation biases are observed across anxiety disorders uniformly or if they vary in extent across diagnostic categories, or if the content of the ambiguous situation (i.e., social vs. non-social) is disorder-specific. Second, while several self-reports of interpretation bias have been developed, their psychometric properties have not been published, the measures combine assessment of interpretations with youth potential responses to approach or avoid (e.g., Miers, Blote, Bögels, \& Westenberg, 2008) resulting in a measure of interpretation and goal selection (stage three of information processing models, and/or questionnaires ask about how likely events are to happen rather than asking youth to attribute meaning to ambiguity (e.g., Pereira, Barros, Mendonca, \& Muris, 2014). Third, vignette-based interpretation bias measures often require coding and interpretation by trained coders, while performance-based interpretation bias measures are not readily available to practicing clinicians. Together, the extant interpretation bias literature is limited in regards to its ability to be applied to nonresearch settings. Below we elaborate on this background and describe how this study aims to expand on these areas.

\section{Current assessment of interpretation bias}

Interpretation bias in youth has been assessed in various modalities. Investigations with computerized, performance-based paradigms have found that anxious young people demonstrate interpretive biases at implicit or automatic (i.e., in less than 3000 milliseconds) stages of cognition (e.g., In-Albon, Klein, Rinc, Becker, \& Schneider, 2008; In-Albon, Dubi, Rapee, \& Silverman, 2009; Rozenman et al., 2014), suggesting that some aspects of interpretation bias occur without awareness. Studies in which responses to ambiguous vignettes are coded by trained assessors for the types of attributions made or outcomes selected by the child have indicated that anxious children and adolescents identify threatening outcomes and subsequently choose more avoidant responses (e.g., Barrett, Rapee, Dadds, \& Ryan, 1996; Bögels, van Dongen, \& Muris, 2003; Creswell \& O'Connor, 2011; Lester, Seal, Nightingale, \& Field, 2010). Performance-based and vignette freeresponse measures may provide a more sophisticated, fine-grained examination of how biased interpretation may lead to and maintain anxiety; however, such measures may be limiting in that they require specialized equipment and/or training of experimenters and coders. Other self-report measures of interpretation bias either provide qualitative data with the potential to endorse more than one response and follow up with queries about selection of avoidant goals (i.e., Miers et al., 2008), which assesses both interpretation bias and goal 
selection stages of information processing. Still yet other measures only provide one threatening and one neutral response from which to choose (i.e., Vassilopoulos \& Banerjee, 2008; Vassilopoulos et al., 2006; Vassilopoulos, Moberly, \& Douratsou, 2011), which may constrain youth responses and provide less accurate information regarding threat-relevant thoughts. Unfortunately, many of the self-report and vignette-based measures are adapted in each new investigation, even by the same investigative team, which limits generalizability of findings to that particular version of the measure. As mentioned above, psychometric properties of many of these measures have not been published.

An additional difficulty in this literature is that self-report questionnaires of global negative self-talk have been called interpretation bias measures. While these questionnaires correlate with youth anxiety symptoms (e.g., Cannon \& Weems, 2010; Schniering \& Rapee, 2002; Suarez \& Bell-Dolan, 2001; Vassilopoulos \& Banerjee, 2012; Weems, Costa, Watts, Taylor, \& Cannon, 2007), items on such questionnaires reflect a general construct of negative cognition linked to negative affect (e.g., "I will never be as good as other kids"), rather than the specific process of attributing emotional or threat valence to outcomes when faced with situational ambiguity (e.g., "Kids are laughing while I'm reading because I made a mistake"). Accordingly, self-reports assessing interpretations of specific types of ambiguity (e.g., specific forms of social threat from peers and adults) would provide a more targeted approach to understanding interpretation bias in anxious children and adolescents.

\section{Specificity of interpretation bias in anxious youth}

In considering interpretation bias, the question of content specificity arises: do all anxious youth demonstrate interpretation bias regardless of ambiguous information presented, or, is interpretation bias specific to the type of ambiguous information and anxiety symptoms? A few investigations have explored these questions and found that, anxious youth, regardless of diagnosis/symptom type, interpret ambiguous social situations as more threatening compared to typically developing non-anxious youth (e.g., Creswell, Murray, \& Cooper, 2013; Muris, Kindt, Bögels, Merckelbach, Gadet, \& Moulaert, 2000). While some work has been done to examine whether social interpretation bias is specific to social anxiety disorder or observed broadly across youth anxiety, findings have generally been mixed. The majority of this work has been conducted in community (non-anxious) samples (Bögels, Snieder \& Kindt, 2012; Creswell \& O'Connor, 2011; Miers et al., 2008; Vassilopoulos \& Banerjee, 2011). Given obvious differences in functioning and symptoms between clinically anxious and community samples, it is unclear whether these mixed findings can be extended to youth who meet criteria for clinical levels of anxiety. In clinically anxious samples, findings have also been mixed, with studies finding socially anxious youth to demonstrate greater social interpretation bias than youth with other anxiety disorders (e.g., generalized, separation; Waite, Codd, \& Cresswell, 2015). Conversely, others have found youth with social anxiety and other anxiety disorders to demonstrate comparable social interpretation biases (Creswell, Murray, \& Cooper, 2014). Thus, the question of whether threat interpretation of social ambiguity is observed in youth with social phobia and/or other anxiety disorders remains. Such information would have clear implications for addressing interpretation bias within cognitive behavioral and novel computerized (e.g., cognitive bias modification) interventions. Therefore, measures of interpretation bias that specifically query social 
ambiguity may provide information about whether threat interpretations for social scenarios are exhibited for only youth with social anxiety or youth with any anxiety disorder, or whether the extent of the bias differs between socially anxious youth and youth with other types of anxiety disorders. A focus on social threat interpretation bias is relevant to both theory-driven research (i.e., models of social information processing in anxiety disorders; Crick \& Dodge, 1994) and clinical practice, as social anxiety is one of the most common anxiety disorders (Beesdo, Knappe, \& Pine, 2009) and predicts later depression (Stein, Fuetsch, Mueller, Lieb, \& Wittchen, 2001) and substance abuse/dependence (e.g., Buckner, Schmidt, Lang, Small, Schlauch, \& Lewinsohn, 2008).

Although current methods for assessing performance-, vignette-based, and self-report interpretation biases have been valuable for studying this cognitive process, there is great potential utility in brief measures of interpretation suitable for use with anxious children and adolescents in both clinic and research settings, where other modalities may not be feasible or sustainable. It is also necessary to test the psychometric properties of such interpretation bias measures prior to widespread use in research and clinical settings. In consideration of recent efforts to target cognitive biases with novel neurocognitive therapies (e.g., cognitive bias modification), assessment of interpretation bias with a variety of modalities may provide an opportunity to test bias change at a variety of levels (e.g., performance-based, validated self-reports). Broadly, a validated self-report measure of social interpretation bias may provide practical and cost-efficient measurement of interpretation bias, which may benefit a range of researchers and practicing clinicians.

\section{Present study}

Langley and colleagues developed the youth Ambiguous Situations Questionnaire (Langley, Bergman, Barrett, \& Piacentini, 2007; unpublished), now renamed the Self-report of Ambiguous Social Situations for Youth (SASSY), to meet this need. The SASSY is a sixitem youth-report questionnaire designed to assess interpretations of ambiguous social situations initially adapted from a family interactions task (Barrett et al., 1996). Barrett's original task involves a trained experimenter reading aloud six vignettes to a child, obtaining the child's free response, asking follow-up questions of the child about his/her response, and then scoring by a coder trained in coding of responses. While the original task and vignettes have been adapted in various ways for other investigations of youth anxiety (e.g., Aschenbrand \& Kendall, 2012; Barrett et al., 1996; Chorpita \& Barlow, 1996; Creswell, Schniering, \& Rapee, 2005), the task is limiting in that it requires at least two trained staff members to administer the vignettes (or play them on an audio recorder) and reliably code youth responses. The SASSY was developed, in part, in an attempt to translate the verballyadministered vignettes into a self-report measure that could more easily be administered to children and adolescents. In consultation with the original author of the vignettes, Langley and colleagues (2007) converted the vignettes into brief sentences describing six ambiguous scenarios each with four multiple choice response options (two threat-relevant and two neutral) for each scenario (see Appendix).

The present study aimed to examine the psychometric properties of the SASSY, youth selfreport measure of social interpretation bias. Specifically, the primary goals of the current 
study were to evaluate the factor structure, internal consistency, and validity (convergent, discriminant, and concurrent criterion) of the SASSY in a sample of children and adolescents who met criteria for an anxiety disorder. Given that the psychometric properties of the SASSY have not yet been tested, in this study we used exploratory factor analysis to evaluate whether the items comprising the SASSY represented a unified construct of social threat interpretation. We hypothesized, based on earlier work by Barrett and colleagues (2005) use vignette- and self-report measures of negative thinking and interpretation bias with samples including children as young as 7 (Barrett, Rapee, Dadds, \& Ryan, 1996), that the items would reflect a single factor of social evaluative threat. In addition, given that the SASSY items are relevant to social ambiguity, a second goal was to explore the degree to which an interpretation bias for social scenarios was sensitive across different anxiety diagnoses; we hypothesized that scores on this measure would demonstrate specificity in predicting a social phobia diagnosis. Finally, we evaluated the potential utility of measuring change in interpretation bias with successful anxiety treatment, and hypothesized that SASSY scores would improve with positive response to intervention.

\section{Materials and Methods}

\section{Participants}

Participants included 488 children ages 7 to 17 (mean age 10.7; SD $=2.8$ years) recruited as part of the Child and Adolescent Anxiety Multimodal Treatment Study (CAMS) across six sites nationwide (for details see Compton et al., 2010 for design, Kendall et al., 2010 for sample characteristics, and Walkup et al., 2008 for intervention outcomes) and their primary parent or caregiver. The study included an even number of boys and girls (49.6\% female). Seventy nine percent of the sample identified themselves as White, with 9\% of participants identifying as African American, 3\% as Asian or Pacific Islander, 1\% as American Indian, and $8 \%$ as Other. Twelve percent of the sample identified as Hispanic, and $21.1 \%$ of families were considered low socioeconomic status according to the Hollingshead socioeconomic status two-factor index (occupation and education; ; score of 1-3 on 1-5 scale) (Hollingshead, 1957).

All participants met DSM-IV criteria for a primary diagnosis of Social Phobia, Generalized Anxiety Disorder, and/or Separation Anxiety. A total of 400 children and adolescents met criteria for Social Phobia, with $\mathrm{n}=247(50.6 \%)$ having a Primary or Co-Primary diagnosis of Social Phobia, and $n=153$ (31.4\%) meeting criteria for secondary Social Phobia with a primary diagnosis of either Generalized Anxiety Disorder and/or Separation Anxiety Disorder. The remaining 88 youth met diagnostic criteria for generalized anxiety, separation anxiety, or both, but not for social phobia. Youth who met diagnostic criteria for any other Axis I disorder requiring treatment were excluded from participating in the study. For more information on the CAMS sample, see Walkup et al., 2008 and Compton et al., 2010.

\section{Procedure}

The SASSY was completed by youths as part of the pre- and post-treatment assessment for CAMS. Participants were randomized and completed 12 weeks of intervention: cognitive behavior therapy (Coping Cat program), medication (sertraline), a combination of cognitive 
behavior therapy + sertraline, or pill placebo. The study was approved by the Institutional Review Boards at each of the six participating University sites and both parental consent and youth assent were obtained.

\section{Measures}

Anxiety Disorders Interview Schedule (ADIS-C/P) (Silverman \& Albano, 1996). The ADIS is a semi-structured interview that assesses the major DSM-IV anxiety, mood, and externalizing disorders experienced by school-aged children and adolescents. In addition to generating DSM-IV diagnoses, interviewers also assigned a clinical severity rating (CSR), based on an 8 -point scale ( $0=$ not at all, $4=$ some, $8=$ very, very much), for each assigned diagnosis (Silverman \& Albano, 1996). Each diagnosis with a CSR of 4 or above indicates a clinically significant disorder. The ADIS has excellent inter-rater reliability, retest reliability, and concurrent validity (Lyneham, Abbott, \& Rapee, 2007; Wood, Piacentini, Bergman, McCracken, \& Barrios, 2002). The intraclass correlation coefficient for the interrater reliability between the CAMS Independent Evaluators and CAMS quality assurance raters was .88 for Separation Anxiety Disorder, .85 for Social Phobia, and .82 for Generalized Anxiety Disorder (Compton et al., 2014). Whenever possible, children and parents were interviewed separately by the independent evaluators.

Self-report of Ambiguous Social Situations for Youth (SASSY; Langley, Bergman, Barrett, \& Piacentini, 2007). The SASSY, originally named the Ambiguous Situations Questionnaire, was derived from the Ambiguous Situations and Family Interactions task (Barrett et al., 1996). The original task included vignettes which were verbally read aloud to the child. The six social vignettes were converted to self-report items, each describing an ambiguous situation involving social threat. Youth select which one of four possible responses best describes what they think is most likely to have happened in each of the six scenarios. Two responses are considered to indicate a benign or neutral interpretation ( 0 points) and two are considered to indicate the presence of a social threat interpretation bias (1 point). To verify this, we asked five pediatric anxiety and child psychiatry experts (Ph.D. or MD level) to review each of the six SASSY items and blindly indicated whether each response represented a "neutral" or "threat" response. Each of the five correctly classified the response type for each response option with $100 \%$ accuracy. Total SASSY scores can range from 0 to 6 . Items are reported in the Appendix.

The Multidimensional Anxiety Scale for Children (MASC; March, Parker, Sullivan, Stallings, \& Conners, 1997) is a 39-item self-report measure of youth anxiety symptoms yielding 4 scale scores and a total score. Each item is rated on a four-point Likert-type response scale ranging from "Never true about me" (0) to "Often true about me" (3). Four main scales include: Social Anxiety (9 items), Separation Anxiety/Panic (9 items), Harm Avoidance (9 items), and Physical Symptoms (12 items). The MASC demonstrates sound psychometric properties (March, Sillivan, \& Parker, 1999; Olason, Sighvatsson, \& Smari, 2004; Rynn et al., 2006) and age- and gender-corrected norms. MASC scores were used in convergent (social anxiety) and discriminant (separation/panic, harm avoidance, physical) validity analyses, and scores on this measure correspond well with diagnoses (Villalbø et al., 2012). Cronbach's alpha for the total MASC in the current sample was .88 . 
Mood and Feelings Questionnaire (MFQ; Wood, Kroll, Moore, \& Harrington, 1995) was used to assess youth depressive symptoms. The MFQ is a 33-item youth -report inventory of depressive symptomatology in children and adolescents. The MFQ has demonstrated sound psychometric properties in both clinical and non-clinical samples of youth (Daviss, Birmaher, Melhem, Axelson, Michaels, \& Brent, 2006; Kent, Vostanis, \& Feehan, 1997; Sund, Larsson, \& Wichstrom, 2001). In this sample, the MFQ had excellent internal consistency with Cronbach's $a=.92$. MFQ scores were used to assess the discriminant validity of the SASSY.

Negative Affectivity Self-Statement Questionnaire (NASSQ; Ronan, Kendall, \& Rowe, 1994) is a 70-item youth-reported questionnaire assessing global negative self-talk, with both anxiety and depression self-statement subscales. The measure contains separate items for school-aged children and adolescents, and has demonstrated strong psychometric properties (Ronan et al., 1994; Lerner et al., 1999). Cronbach's alpha for the NASSQ total score in this sample was .94. It should be noted that the NASSQ was developed not as a measure of anxiety or depression symptoms per se, but as a measure of negative self-talk that may occur as a function of negative affect. Given that negative thinking may be one form of interpretation bias, in this study the NASSQ was used for convergent validity purposes.

Clinical Global Impressions - Improvement (CGI-I; Guy, 1976) was used to assess treatment response at post-treatment assessment. The CGI-I is a clinician-rated categorical measure of global improvement. Participants with CGI-I scores of 1 ("very much improved") or 2 ("much improved") were considered treatment responders. The CGI-I responder status was utilized as a predictor of interpretation bias change from pre-to-post treatment in analyses examining sensitivity to intervention response, with intervention response (CGI-I $\leq 2)$ indicating clinically significantly symptom reduction.

\section{Data Analytic Plan}

Analyses were completed using SPSS (Version 22.0) and Mplus Version 7 (Muthén \& Muthén, 2012). Exploratory factor analyses was conducted to evaluate the dimensionality of the six-item SASSY. EFA was conducted in Mplus using robust weighted least squares (WLSMV), which estimates a tetrachoric correlation matrix for factor extraction in these data with binary item responses. An oblique rotation (CF-Equamax; see Sass \& Schmitt, 2010) was used to allow for correlated factors. We examined rotated loadings, factor correlation, factor structure matrix (correlations between variables and factors), and pattern matrix (standardized coefficients). Given the large sample size $(\mathrm{N}>450)$, we used a criterion of loading $>\mid .32$ to determine a significant factor loading (Tabachnik \& Fidell, 2013). Because we used oblique rotation for correlated factors, we did not interpret variance explained by each factor. Following the suggestion of $\mathrm{Hu}$ and Bentler (1999), model fit was evaluated with an incremental and absolute fit index, Root Mean Square Error of Approximation (RMSEA; value of <.05 indicates a good fit), and the Comparative Fit Index and Tucker Lewis Fit Index (CFI; TFI; values of >.90 indicate a good fit), respectively, in addition to the chi-square test of model fit. Determination of the number of factors was multifaceted and considered descriptive indices of model fit (RMSEA), scree test, the 
"cleanness" of the factors (i.e., loadings $\geq .32$, no cross-loadings, at least three items; Costello \& Osborn, 2005), and the conceptual meaning/interpretability of factors. Internal consistency was evaluated using the Kuder-Richardson 20 (KR-20) coefficient for dichotomous item responses.

Correlational analyses were performed to examine convergent and discriminant validity with measures of similar and unrelated constructs, respectively, and logistic regression was used to examine whether SASSY scores predicted concurrent diagnostic status for Social Phobia. Because the large number of correlations examined and large sample size were likely to lead to many significant results, we employed a conservative approach to interpret significance, with a Bonferroni corrected $p<.0018$ (28 total correlations) to determine significant correlations between SASSY scores and other measures to minimize the potential for Type I error. Repeated-measures ANCOVA was performed to assess sensitivity to post-intervention threat interpretation bias change by examining differences in pre- to post-intervention reductions in SASSY scores between intervention responders (CGI-I $\leq 2$ ) and nonresponders (CGI-I > 2).

\section{Results}

SASSY total score was not significantly correlated with socioeconomic status $(\mathrm{r}=-.04, p$ $=.36)$. There was a significant correlation between youth age and SASSY total score ( $r=$. $20, p<.001$, small effect). Independent sample T-tests showed no significant differences based on youth gender ( $\mathrm{t}(486)=-1.62, p=.11$, Cohen's $d=.15)$ or ethnicity $\left(\mathrm{F}_{5,482}=1.30\right.$, $p=0.26$ ). Because SASSY total score was significantly correlated with age, all subsequent regression analyses included age as a covariate.

\section{Exploratory factor analysis}

An EFA of the SASSY supported both a one-factor, $\chi_{(\mathrm{df}=9)}^{2}=8.35, p=0.49, \mathrm{CFI}=1.00$, $\mathrm{TLI}=1.00$, RMSEA $<.001,(90 \% \mathrm{CI}: 0.00,0.04)$ and a two-factor solution,$\chi^{2}(\mathrm{df}=4)=$ $2.50, p=0.65, \mathrm{CFI}=1.00, \mathrm{TLI}=1.02, \mathrm{RMSEA}<.001$, (90\% CI: $0.00,0.06)$. Using the rotated pattern matrix for interpretation, all pattern coefficients were large and positive for the single factor solution. Similarly, three pattern coefficients were large and positive for both factors in the two-factor solution, meeting our a priori practical significance value of $>\mid$. 32|; values ranged from .33-.63 for factor 1, and .34-.63 for factor 2 (presented in Table 1, along with standard errors and unstandardized loadings). Factor 1 represents Social Blame/ Accusation, and Factor 2 represents Social Rejection ${ }^{1}$. As predicted, the two factors were positively correlated $(r=0.56)$. Examination of the standard loadings indicated that two items on Factor 1 were not statistically significant (standardized loadings $<1.96$ ) although they met our criteria for practical significance (>.32) and did not cross-load onto Factor 2 with both values below our criteria of .32 . These findings indicate a two-factor solution, with Factor 2 being a particularly strong factor, and weaker support for Factor 1. Sample means

\footnotetext{
${ }^{1}$ To reduce subjectivity of the factor names, we showed the two groups of items to five child psychologists and psychiatrists and asked them what they would name each factor. For Factor 1 (Accusation/Blame), we got responses such as "Fear of punishment" or "Negative Attributions" or "Blame." All of these responses are consistent with our naming. Similarly, for Factor 2 (Social Rejection), each expert stated either "social rejection" or "peer rejection."
} 
for the SASSY total, and the Social Rejection and Accusation/Blame subscale, are displayed in Table 2. For descriptive purposes, Means and SDs are listed for youths with primary, coprimary, and no Social Phobia. SASSY total and Social Rejection subscale scores were significantly higher for youth with primary or co-primary social phobia compared to anxious youth who did not meet diagnostic criteria for social phobia.

\section{Internal Consistency}

Internal consistency estimates for the resulting six-item measure, as well as the two threeitem subscales, were examined. The full 6-item total measure demonstrated an internal consistency of $r_{\mathrm{KR}-20}=.64$, and item-to-total remainder correlations (e.g., correlation between each item and the total score excluding that item) ranging from .29-.67 (Table 3). Endorsement frequency for individual items ranged from 14-52\% (Table 3); approximately $75.8 \%$ of youths endorsed at least one threat interpretation response for any of the six items. Internal consistency for the subscales was $r_{\mathrm{KR}-20}=.43$ for Social Blame/Accusation and $r_{\mathrm{KR}-20}=.56$ for Social Rejection. Both subscale scores were highly correlated with the SASSY total score (both $r>.82, p<0.001$ ).

\section{Criterion Validity}

Binomial logistic regression assessed how well the SASSY total and subscale scores predicted the presence/absence of a Social Phobia diagnosis. Controlling for the significant effects of age $\left(\beta=1.18, \mathrm{SE}=.05, p<.001\right.$, Nagelkerke $\left.\mathrm{R}^{2}=.05\right)$, SASSY total score reliably and significantly distinguished children and adolescents with and without a diagnosis of Social Phobia (OR $=1.23,95 \%$ CI: 1.04, 1.43, $p=0.02)$, with the full model accounting for $11 \%\left(\beta=1.18, \mathrm{SE}=.05, p<.001\right.$, Nagelkerke $\left.\mathrm{R}^{2}=.11\right)$ of variance in anxiety diagnostic status. Again, controlling for the significant effects of age (two subscales were separately examined as potential predictors of Social Phobia diagnosis; the three-item Social Rejection subscale significantly predicted the presence or absence of Social Phobia diagnosis $(\mathrm{OR}=1.36,95 \% \mathrm{CI}: 1.00,1.80, p=0.03)$, although the Blame/Accusation subscale did not $(\mathrm{OR}=1.05,95 \%$ CI: $0.76,1.44, p=0.77)$.

\section{Convergent and Discriminant Validity}

Correlations between SASSY total and subscale scores, as well as other clinical measures, are displayed in Table 4. Using a criterion of $p<.0018$, SASSY total score was significantly correlated with the MASC total score $(r=.25, p<.001$, small effect), and the MASC Social Anxiety $(r=.36, p<.001$, medium effect) and Physical Symptoms $(r=.19, p<.001$, small effect) Main Factor t-scores, but not with the Separation Anxiety/Panic $(r=.07, p=.11)$ or Harm Avoidance $(r=.04, p=.35)$ Main Factor t-scores. Similarly, the SASSY total score demonstrated medium and significant correlations with the NASSQ Anxiety Scale ( $r=.38, p$ $<.001$, medium effect), Depression Scale ( $r=.34, p<.001$, medium effect), and Negative Affect Scale $(r=.31, p<.001$, medium effect). The SASSY was not significantly correlated with the MFQ, suggesting specificity of the measure to anxiety symptoms (Table 4). This pattern of correlations was identical between the SASSY total score and Social Rejection subscales. The Accusation/Blame subscale demonstrated similar, but smaller and less significant, correlations (see Table 4). 


\section{Sensitivity to symptom change}

Because the SASSY has relevance to children and adolescents with a diagnosis of Social Phobia, we examined sensitivity of the measure to intervention response (i.e., symptom improvement) within a subsample of participants with a diagnosis of Social Phobia ( $\mathrm{N}=$ 400). A repeated-measures ANCOVA with treatment responder status as a predictor and age as covariate revealed that SASSY total score reductions at week 12 (post-intervention) were significantly greater for treatment responders than non-responders (i.e., youths with significant reduction in social anxiety), $F_{1,397}=7.06, p=.008$, partial eta squared $=.02$, small effect. These analyses suggested that for socially anxious youngsters, reductions in total SASSY scores paralleled meaningful reductions in anxiety.

\section{Discussion}

This study describes the initial psychometric properties of a new self-report measure of youth social threat interpretation bias within a clinically-referred sample of children and adolescents with anxiety disorders. Broadly, the SASSY demonstrated favorable psychometric properties and demonstrated adequate internal consistency (for the total score) and good validity. A two-factor solution emerged, with three items each: Social Rejection (i.e., interpretations consistent with rejection and exclusion by peers) and Accusation/Blame (i.e., interpretations consistent with fear of being blamed or blaming others for doing something wrong). The properties of these subscales were generally favorable and similar to those of the full scale. The Social Rejection subscale in particular demonstrated sensitivity to symptom change in youth with diagnoses of Social Phobia.

Although the SASSY could arguably fit one single factor, we tentatively accept a two-factor solution for several reasons. First, the two-factor model is an excellent fit, with all items meeting our minimum factor loading criteria, with no cross-factor loadings. Second, the two factors are conceptually meaningful. The Social Rejection factor performed well within this sample of anxious youth, the majority of whom met diagnostic criteria for social phobia. The Blame/Accusation factor, on the other hand, did not discriminate youth with and without social phobia, though it did converge with other measures of internalizing symptomatology. Notably, only a small percentage of the current sample met DSM-IV criteria for a comorbid diagnosis of ADHD or Oppositional Defiant Disorder (10\% or less). Theoretical models of social information processing biases have been consistently supported by empirical data indicating that both anxious and externalizing/aggressive youth attribute threatening meaning to ambiguous social scenarios (although their responses differ in that anxious youth avoid while externalizing/aggressive youth react (e.g., Crick \& Dodge, 1996; Dodge, 2006). Given these findings that youths with behavioral difficulties exhibit and selfreport negative attributions when asked to interpret the actions of others (typically accusations of blame or perceptions that they are being blamed), it may be possible that the items on the Blame/Accusation scale might assess related aspects of social information processing and that the psychometric properties of this scale may be more robust in a sample of children and adolescents with a larger proportion and higher levels of disruptive/ aggressive behavior problems. Further, the present sample was rather homogenous with respect to anxiety symptomatology (i.e., many youth were socially anxious) which may have 
resulted in low estimates of factor loadings (Fabrigar, Wegener, MacCallum, \& Strahan, 1999). Accordingly, based on our preliminary results we retain the two-factor solution pending replication with a broader sample of youths with non-anxiety psychological disorders.

Internal consistency was adequate for the SASSY total score. Internal consistency for the SASSY subscales was below acceptable levels, particularly for the Blame/Accusation scale. However, this must be interpreted in light of the small number of items (i.e., three items per subscale), which influences the Cronbach's alpha reliability coefficient (Graham, 2006). Examination of frequency of item endorsement indicated that most anxious children and adolescents endorsed at least one threat item, although a lower percentage of youth endorsed items on the Blame/Accusation subscale (Table 3). Additionally, both subscales were significantly correlated with the SASSY total score. Results support acceptable convergent and discriminant validity of the SASSY and its subscales. Youth with higher levels of social threat interpretation as rated by parents and youth demonstrated elevated scores on self- and parent-reported measures of social anxiety, and did not show significant elevation for separation and panic worries, harm avoidance, or depressive symptoms. Although the SASSY significantly correlated with measures of physical symptoms, these effects were smaller than those observed with social anxiety measures. These findings suggest that the SASSY is specific to social anxiety threat bias, or that the extent of its relevance is greater for social phobia than other forms anxiety. Further, results support the criterion validity of the SASSY total and Social Rejection subscale; each distinguished between youth with and without a diagnosis of Social Phobia within this clinically anxious sample, demonstrating the specificity of this social threat interpretation measure to pediatric social phobia. This extends previous findings that interpretation of social threat from ambiguity is present across anxiety disorder diagnoses and suggests that interpretation of social threat is greater in children with social phobia than other anxiety disorders. Finally, the SASSY demonstrated sensitivity to symptom improvement, as indicated by intervention response in the CAMS (2008) randomized trial, although these effects were small.

In sum, results provide psychometric support for the SASSY full scale and Social Rejection subscale, and weaker support for the Blame/Accusation subscale. Certain methodological limitations must be noted when interpreting these results. All participants in this sample met criteria for a primary DSM-IV anxiety disorder, with a large proportion meeting diagnostic criteria for social phobia (50\% with primary social phobia, $82 \%$ with any social phobia). Although this proportion appears high, the proportion of youth with principle social phobia is comparable to several studies of anxious youth (e.g., 39\% and 46\%, Kendall et al., 2008 and Wergeland et al., 2014, respectively). Nevertheless, the next step in examining psychometric properties of the SASSY will be to determine the utility of the SASSY in identifying socially anxious children from youth with non-anxiety disorders and children without psychiatric problems. Additionally, the number of children and adolescents without a social phobia diagnosis in the current sample was small (18\%), so while we were able to distinguish Social Phobia, exploring the psychometric properties of the SASSY among a large number of anxious children and adolescents without Social Phobia is necessary to further examine the specificity of the SASSY to social phobia versus anxiety disorders more broadly. As previously mentioned, replication studies involving non-anxious youth are 
needed to determine the utility of the Accusation/Blame subscale which may be relevant to the assessment of youngsters with a broader range of behavioral and emotional difficulties (e.g., externalizing problems). In addition, the majority of youth in this study were nonHispanic White, and research on the psychometric properties of the SASSY in non-White ethnic groups is needed to demonstrate whether the measure is culturally sensitive in assessing social threat interpretation bias. Finally, as prior studies have found mixed results in regards to whether younger children demonstrate social interpretation bias, future investigations might also compare children and adolescents on the SASSY in both clinical and non-clinical samples.

\section{Implications}

Research on interpretation bias can have theoretical implications on our understanding of cognitive vulnerability factors as well as practical implications in the assessment and treatment of anxiety and comorbid conditions. From a theoretical perspective, future work with more clinically diverse samples is needed to clarify the potential role of social threat interpretation bias as a transdiagnostic marker across psychopathology, which would have useful applications for the development of interventions. While attention bias is not a ubiquitous phenomenon in youth, interpretation bias has been found to predict a substantial proportion of variance in anxiety symptoms within anxious samples (Rozenman, Amir, \& Weersing, 2014) and is similar, if not the same, as "hostile attribution bias" or "social information processing bias" in disruptive and aggressive youth samples (Dodge \& Crick, 1990; De Castro, Veerman, Koops, Bosch, \& Monshouwer, 2002). Thus, the relevance of interpretation bias across internalizing and externalizing behaviors suggests that interpretation bias may be a transdiagnostic marker underlying various forms of psychopathology, while there may be content specificity, such that the content of the ambiguous information presented may be a specific predictor of specific problems (e.g., social threat interpretation and social phobia). Accordingly, future research should examine the performance of the full SASSY in internalizing, externalizing, and comorbid internalizing/externalizing samples. In addition, future research evaluating the linkages between social threat interpretation biases and similar but distinct constructs, such as intolerance of uncertainty or ambiguity, may provide a fuller understanding of cognitive vulnerability factors that underlie various forms of psychopathology.

From a practical perspective, although more research is needed, the current study provides preliminary support for the potential utility of the SASSY in assessing social threat interpretation bias among children and adolescents with clinically-significant social anxiety. The brevity of this self-report in particular makes it a useful research tool for studying the relationship between social interpretation bias and anxiety symptomatology. The SASSY may also have merit in studies examining the predictive role that threat bias has been presumed to play both in the development of anxiety and treatment response (e.g. Field \& Field, 2013; Rozenman, Amir, \& Weersing, 2014). In practice, the SASSY may be useful in identifying social threat bias in anxious children and adolescents and tracking interpretation bias reduction alongside social anxiety symptom reduction. Although it is premature to recommend use of the SASSY as a screening or therapeutic tool (pending replication with more diverse clinical samples), the clinical assessment of social threat bias may assist CBT 
therapists in determining both specific targets for cognitive restructuring in treatment and response to these interventions.

\section{Acknowledgments}

Funding:

This research was supported by funding by the National Institute of Mental Health (U01MH064089 to Dr. Walkup; U01MH64092 to Dr. Albano; U01MH64003 to Dr. Birmaher; U01MH63747 to Dr. Kendall, U01MH64088 to Dr. Piacentini; U01MH064003 to Dr. Compton, T32MH073517 to support Dr. Gonzalez, and T32MH017140 to support Dr. Rozenman) from the National Institute of Mental Health. Views expressed within this article represent those of the authors and are not intended to represent the position of NIMH, NIH, or DHHS.

\section{References}

Achenbach, TM. Integrative guide for the 1991 CBCL/4-18, YSR and TRF profiles. Burlington: Department of Psychiatry, University of Vermont; 1991.

Achenbach, TM., Rescorla, LA. The manual for the ASEBA school-age forms \& profiles. Burlington, VT: University of Vermont, Research Center for Children, Youth, and Families; 2001.

Barrett PM, Rapee RM, Dadds MM, Ryan SM. Family enhancement of cognitive style in anxious and aggressive children. Journal of Abnormal Child Psychology. 1996; 24:187-199. [PubMed: 8743244]

Beesdo K, Knappe S, Pine DS. Anxiety and anxiety disorders in children and adolescents: Developmental issues and implications for DSM-V. Psychiatric Clinics of North America. 2009; 32:483-524. [PubMed: 19716988]

Blossom JB, Ginsburg GS, Birmaher B, Walkup JT, Kendall PC, Albano AM. Parental and family factors as predictors of threat bias in anxious youth. Cognitive Therapy and Research. 2013; 37:812-819. [PubMed: 25328258]

Bögels SM, van Dongen L, Muris P. Family influences on dysfunctional thinking in anxious children. Infant and Child Development. 2003; 12:243-252.

Cannon MF, Weems CF. Cognitive biases in childhood anxiety disorders: Do interpretive and judgment biases distinguish anxious youth from their non-anxious peers? Journal of Anxiety Disorders. 2010; 24:751-758. [PubMed: 20554426]

Compton SN, Walkup JT, Albano AM, Piacentini JC, Birmaher B, March JS. Child/Adolescent Anxiety Multimodal Study (CAMS): Rationale, design, and methods. Child and Adolescent Psychiatry and Mental Health. 2010; 4:1. http://www.capmh.com/content/4/1/1. [PubMed: 20051130]

Compton SN, Peris TS, Almirall D, Birmaher B, Sherrill J, Albano AM. Predictors and Moderators of Treatment Response in Childhood Anxiety Disorders: Results from the CAMS Trial. Journal of Consulting and Clinical Psychology. 2014; 82:212-224. [PubMed: 24417601]

Costello EJ, Egger HL, Angold A. 10-year research update review: The epidemiology of child and adolescent psychiatric disorders: I. Methods and public health burden. Journal of the American Academy Child and Adolescent Psychiatry. 2005; 44:972-986.

Costello AB, Osborne JW. Best practices in exploratory factor analysis: four recommendations for getting the most from your analysis. Practical Assessment Research \& Evaluation. 2005; 10(7) Available online: http://pareonline.net/getvn.asp?v=10\&n=7.

Creswell C, Apetroaia A, Murray L, Cooper P. Cognitive, affective, and behavioral characteristics of mothers with anxiety disorders in the context of child anxiety disorder. Journal of Abnormal Psychology. 2013; 122:26-38. [PubMed: 22905861]

Creswell C, Murray L, Cooper P. Interpretation and expectation in childhood anxiety disorders: Age effects and social specificity. Journal of Abnormal Child Psychology. 2013; 42:453-465.

Creswell C, O'Connor TG. Interpretation bias and anxiety in childhood: Stability, specificity and longitudinal associations. Behavioural and Cognitive Therapy. 2011; 39:191-204. 
Crick NR, Dodge KA. A review and reformulation of social information-processing mechanisms in children's social adjustment. Psychological Bulletin. 1994; 115:74-101.

Daleiden EL, Vasey MW. An information-processing perspective on childhood anxiety. Clinical Psychology Review. 1997; 17:407-429. [PubMed: 9199859]

Davis WB, Birmaher B, Melhem NA, Axelson DA, Michaels SM, Brent DA. Criterion validity of the Mood and Feelings Questionnaire for depressive episodes in clinic and non-clinic subjects. Journal of Child Psychology and Psychiatry. 2006; 47:927-934. [PubMed: 16930387]

Dodge KA. Translational science in action: Hostile attributional style and the development of aggressive behavior problems. Development and Psychopathology. 2006; 18:791-814. [PubMed: 17152401]

Fabrigar LR, Wegener DT, MacCallum RC, Strahan EJ. Evaluating the use of exploratory factor analysis in psychological research. Psychological Methods. 1999; 4(3):272-299.

Field AP, Lester KJ. Is there room for 'development' in developmental models of information processing biases to threat in children and adolescents? Clinical Child and Family Psychology Review. 2010; 13:315-332. [PubMed: 20811944]

Gonzalez A, Peris TS, Vreeland A, Kiff CJ, Kendall PC, Compton SN, Piacentini JC. Parental anxiety as a predictor of medication and CBT response for anxious youth. Child Psychiatry \& Human Development. 2014 Advance online publication.

Graham JM. Congeneric and (essentially) tau-equivalent estimates of score reliability: What they are and how to use them. Educational and Psychological Measurement. 2006; 66:930-944.

Guy, W. The ECDEU Assessment Manual for Psychopharmacology-Revised. (DHEW, Publ No ADM 76-338). Rockville, MD: U.S. Department of Health, Education, and Welfare Public Health Service, Alcohol, Drug Abuse, Mental Health Administration, NIMH Psychopharmacology Research Branch, Division of Extramural Research; 1976. The clinical global impression scale; p. 218-222.

Hadwin J, Frost S, French CC, Richards A. Cognitive processing and trait anxiety in typically developing children: Evidence for an interpretation bias. Journal of Abnormal Psychology. 1997; 106:486-490. [PubMed: 9241952]

Hadwin JA, Garner M, Perez-Olivas G. The development of information processing biases in childhood anxiety: A review and exploration of its origins in parenting. Clinical Psychology Review. 2006; 26:876-894. [PubMed: 16524655]

Hollingshead, AB. Two factor index of social position. New Haven: Privately printed; 1957.

$\mathrm{Hu}$ LT, Bentler PM. Cutoff criteria for fit indexes in covariance structure analysis: Conventional criteria versus new alternatives. Structural Equation Modeling: A Multidisciplinary Journal. 1999; $6(1): 1-55$.

In-Albon T, Dubi K, Rapee R, Schneider S. Forced choice reaction time paradigm in children with separation anxiety disorder, social phobia, and nonanxious controls. Behaviour Research and Therapy. 2009; 47:1058-1065. [PubMed: 19733835]

In-Albon T, Klein A, Rinck M, Becker E, Schneider S. Development and evaluation of a new paradigm for the assessment of anxiety disorder-specific interpretation bias using picture stimuli. Cognition and Emotion. 2008; 22:422-436.

Kendall PC, Hudson JL, Gosch E, Flannery-Schroeder E, Suveg C. Cognitive-behavioral therapy for anxiety disordered youth: A randomized clinical trial evaluating child and family modalities. Journal of Consulting and Clinical Psychology. 2008; 76(2):282-297. [PubMed: 18377124]

Kendall, PC. Treating anxiety disorders in youth. In: Kendall, PC., editor. Child and adolescent therapy: Cognitive-behavioral procedures. 4th. New York: Guilford Press; 2012.

Kendall PC, Compton SN, Walkup JT, Birmaher B, Albano AM, Sherrill J, Piacentini J. Clinical characteristics of anxiety disordered youth. Journal of Anxiety Disorders. 2010; 24:360-365. [PubMed: 20206470]

Kent L, Vostanis P, Feehan C. Detection of major and minor depression in children and adolescents: Evaluation of the Mood and Feelings Questionnaire. Journal of Child Psychology and Psychiatry. 1997; 38:565-573. [PubMed: 9255700]

Langley, Bergman, Barrett, Piacentini. Ambiguous Situations Self-Report for Children and Adolescents. 2007. Unpublished 
Lester KJ, Field AP, Oliver S, Cartwright-Hatton S. Do anxious parents interpretive biases towards threat extend into their child's environment? Behaviour Research and Therapy. 2009; 47:170-174. [PubMed: 19117552]

Lester KJ, Seal K, Nightingale ZC, Field AP. Are children's own interpretations of ambiguous situations based on how they perceive their mothers have interpreted ambiguous situations for them in the past? Journal of Anxiety Disorders. 2010; 24:102-108. [PubMed: 19815372]

March JS, Parker JDA, Sullivan K, Stallings P, Conners C. The Multidimensional Anxiety Scale for Children (MASC): Factor structure, reliability, and validity. Journal of the American Academy of Child \& Adolescent Psychiatry. 1997; 36:554-565. [PubMed: 9100431]

March JS, Sullivan K, Parker J. Test-retest reliability of the Multidimensional Anxiety Scale for Children. Journal of Anxiety Disorders. 1999; 13:349-358. [PubMed: 10504106]

Merikangas KR, He J, Burstein M, Swanson SA, Avenevoli S, Swendsen J. Lifetime prevalence of mental disorders in U.S. adolescents: Results from the National Comorbidity Survey Replication Adolescent Supplement (NCS-A). Journal of the American Academy of Child \& Adolescent Psychiatry. 2010; 49(10):980-989. [PubMed: 20855043]

Muris P, Field AP. Distorted cognition and pathological anxiety in children and adolescents. Cognition \& Emotion. 2008; 22:395-421.

Muris P, Kindt M, Bögels S, Merckelbach H, Gadet B, Moulaert V. Anxiety and threat perception abnormalities in normal children. Journal of Psychopathology and Behavioral Assessment. 2000; 22:183-199.

Muris P, Rapee R, Meesters C, Schouten E, Geers M. Threat perception abnormalities in children: the role of anxiety disorders symptoms, chronic anxiety, and state anxiety. Journal of Anxiety Disorders. 2003; 17:271-287. [PubMed: 12727122]

Muthén, LK., Muthén, BO. Mplus User’s Guide. Seventh. Los Angeles, CA: Muthén \& Muthén; 2012.

Olason DT, Sighvatsson MB, Smari J. Psychometric properties of the Multidimensional Anxiety Scale for Children (MASC) among Icelandic schoolchildren. Scandinavian Journal of Psychology. 2004; 45:429-436. [PubMed: 15535811]

Ronan KR, Kendall PC, Rowe M. Negative affectivity in children: Development and validation of a self-statement questionnaire. Cognitive Therapy and Research. 1994; 18:509-528.

Rozenman M, Amir N, Weersing VR. Performance-based interpretation bias in clinically anxious youths: Relationships with attention, anxiety, and negative cognition. Behavior Therapy. 2014; 45:594-605. [PubMed: 25022771]

Rynn MA, Barber JP, Khalid-Khan S, Siqueland L, Dembiski M, McCarthy KS, Gallop R. The psychometric properties of the MASC in a pediatric psychiatry sample. Journal of Anxiety Disorders. 2006; 20:139-157. [PubMed: 16464701]

Sass DA, Schmitt TA. A comparative investigation of rotation criteria within exploratory factor analysis. Multivariate Behavioral Research. 2010; 45(1):73-103. [PubMed: 26789085]

Schniering CA, Rapee RM. Development and validation of a measure of children's automatic thoughts: The Children's Automatic Thoughts Scale. Behaviour Research \& Therapy. 2002; 40:1091-1109. [PubMed: 12296494]

Silverman, WK., Albano, AM. The Anxiety Disorders Interview Schedule for DSM-IV-Child and Parent Versions. San Antonio, TX: The Psychological Corporation; 1996.

Silverman, WK., Albano, AM. The Anxiety Disorders Interview Schedule for DSM-IV, Research and Lifetime Version for children and parents (ADIS-RLV). Columbia University, NY: 2002. Unpublished manuscript

Suarez L, Bell-Dolan D. The relationship of child worry to cognitive biases: Threat interpretation and likelihood of event occurrence. Behavior Therapy. 2001; 32:425-442.

Sund AM, Larsson B, Wichstrom L. Depressive symptoms among young Norwegian adolescents as measured by the Mood and Feelings Questionnaire (MFQ). European Child \& Adolescent Psychiatry. 2001; 10:222-229. [PubMed: 11794547]

Tabachnik, BG., Fidell, LS. Using Multivariate Statistics. Sixth. Boston: Pearson; 2013.

Vassilopoulos S, Banerjee R. Social anxiety and content specificity of interpretation and judgmental bias in children. Infant and Child Development. 2012; 21:298-309. 
Villalbø MA, Gere MK, Torgersen S, March JS, Kendall PC. Diagnostic efficiency of the child and parent versions of the Multidimensional Anxiety Scale for Children (MASC). Journal of Clinical Child and Adolescent Psychology. 2012; 41:75-85. [PubMed: 22233247]

Walkup JT, Albano AM, Piacentini J, Birmaher B, Compton SN, Sherrill JT, Kendall PC. Cognitive behavioral therapy, sertraline, or a combination in childhood anxiety. New England Journal of Medicine. 2008; 359(26):2753-2766. [PubMed: 18974308]

Weems CF, Costa NM, Watts SE, Taylor LK, Cannon MF. Cognitive errors, anxiety sensitivity, and anxiety control beliefs: Their unique and specific associations with childhood anxiety symptoms. Behavior Modification. 2007; 31:174-201. [PubMed: 17307934]

Wergeland GJH, Fjermestad KW, Marin CE, Bjelland I, Haughland BSM, Silverman WK, et al. Predictors of treatment outcome in an effectiveness trial of cognitive behavioral therapy for children with anxiety disorders. Behaviour Research and Therapy. 2016; 76:1-12. [PubMed: 26583954]

Wood A, Kroll L, Moore A, Harrington R. Properties of the mood and feelings questionnaire in adolescent psychiatric outpatients: A research note. Journal of Child Psychology and Psychiatry. 1995; 36:327-334. [PubMed: 7759594]

Wood J, Piacentini J, Bergman RL, McCracken J, Barrios V. Construct validity of the anxiety disorders section of the Anxiety Disorders Interview Schedule for DSM-IV: Child and parent versions. Journal of Clinical Child and Adolescent Psychology. 2002; 31:335-342. [PubMed: 12149971]

\section{Appendix: SASSY Items}

1. You notice at school one day that a favorite book of yours is missing. Later you notice a boy/girl in your class has a similar book in their bag. What do you think is most likely to have happened to your book?

That child has stolen the book and put it in their bag.

Someone who doesn't like you has taken your book so you will be in trouble with your parents.

You left your book at home.

A friend borrowed the book thinking you wouldn't mind.

2. You see the School Principal walking around the playground and s/he has been asking other children where you are. Why do you think the Principal is most likely looking for you?

The principal has a message for you.

The principal thinks you have done something wrong and is angry.

The principal wants to tell you he/she has noticed you are working harder and is pleased.

One of the other children has told the teachers something bad about you.

3. You arrange to have a party at 4:00pm and by 4:30pm no one has arrived. What do you think is most likely to have happened?

Your friends are angry at you and don't want to come.

You must have put $4: 30 \mathrm{pm}$ on the invitation.

Your friends are late because the traffic is very heavy.

Your friends don't want to come because they think it will be really boring.

4. You are showing your school project in front of the class and two students in the back are giggling. What is the reason that they are giggling?

They think the project is really dumb.

They are being silly and tickling each other.

Another kid is making funny faces at them.

There is a big stain on your uniform and they are laughing at you.

5. You are sleeping over at a friend's place and his/her parents seem to be really annoyed and cranky all the time. What is the most likely reason that your friend's parents are annoyed and cranky all the time? 
They had a little argument and are a bit upset with each other.

They don't really like you.

They think you have done something wrong.

They had a party last night and they are tired and don't feel well.

6. You see a group of students from another class playing a great game. You walk over and want to join in and you hear them laughing. Which of the following do you think is most likely to happen next?

They are going to start looking at you and telling secrets about you.

They will soon ask you to join in.

One of them is likely to rush up and push you away.

They are going to notice you and smile. 
Table 1

SASSY factor loadings, standard errors, and unstandardized loadings (CF-Equamax oblique rotation)

\begin{tabular}{lcccc}
\hline & \multicolumn{4}{c}{ Youth Report } \\
\hline & Factor 1 (Blame/Accusation) & $\begin{array}{c}\text { Factor 2 } \\
\text { (Social Rejection) }\end{array}$ \\
\hline Item & $\begin{array}{c}\text { Factor } \\
\text { Loading } \\
\text { (SE) }\end{array}$ & $\begin{array}{c}\text { Unstandardized } \\
\text { Loading }\end{array}$ & $\begin{array}{c}\text { Factor } \\
\text { Loading } \\
\text { (SE) }\end{array}$ & $\begin{array}{c}\text { Unstandardized } \\
\text { Loading }\end{array}$ \\
\hline 1. School book missing & $\mathbf{0 . 6 3}(.18)$ & 3.56 & $-0.03(.05)$ & -0.65 \\
2. School principal asking for you & $\mathbf{0 . 3 3}(.17)$ & 1.94 & $0.12(.18)$ & 0.67 \\
3. No one arrived to party & $0.05(.15)$ & 0.31 & $\mathbf{0 . 3 8}(.15)$ & 2.56 \\
4. School project, students giggling & $0.01(.07)$ & 0.14 & $\mathbf{0 . 6 3}(.15)$ & 4.14 \\
5. Friend's parents annoyed & $\mathbf{0 . 3 7}(.20)$ & 1.86 & $0.27(.21)$ & 1.31 \\
6. Playing game, students laughing & $0.25(.16)$ & 1.50 & $\mathbf{0 . 3 4}(.17)$ & 2.01 \\
\hline
\end{tabular}

SASSY = Self-report of Ambiguous Social Situations for Youth 


\section{Table 2}

SASSY Means (Standard Deviations) for children and adolescents with Primary/Co-Primary Social Phobia, Non-Primary Social Phobia, and No Social Phobia.

\begin{tabular}{lcccc}
\hline & $\begin{array}{c}\text { Total Sample } \\
(\mathbf{n = 4 8 8})\end{array}$ & $\begin{array}{c}\text { Primary or Co- } \\
\text { Primary SP } \\
(\mathbf{n}=\mathbf{2 4 7})\end{array}$ & $\begin{array}{c}\text { Non-Primary } \\
\mathbf{S P}(\mathbf{n = 1 5 3})\end{array}$ & No SP $(\mathbf{n}=\mathbf{8 8})$ \\
\hline SASSY - Total & $1.93(1.63)$ & $2.11^{\mathrm{a}}(1.63)$ & $1.92(1.65)$ & $1.47^{\mathrm{a}}(1.50)$ \\
SASSY-C - Blame/Accusation & $.80(.89)$ & $.82(.88)$ & $.86(.92)$ & $.67(.83)$ \\
SASSY-C - Social Rejection & $1.12(1.02)$ & $1.27^{\mathrm{b}}(1.04)$ & $1.06(1.00)$ & $.81^{\mathrm{b}}(.98)$ \\
\hline
\end{tabular}

SP $=$ Social Phobia; SASSY= Self-report of Ambiguous Social Situations for Youth.

Note: Values in the same row with the same superscript significantly differ at $\alpha=.05(p<.05)$ 
Table 3

SASSY Response Frequency and Item-to-Total Remainder Correlations

\begin{tabular}{lcc}
\hline Item & $\begin{array}{c}\text { \% Endorsing } \\
\text { Threat Response }\end{array}$ & $\begin{array}{c}\text { Item-to-total } \\
\text { Remainder } \\
\text { Correlation }\end{array}$ \\
\hline 1. School book missing & $39 \%$ & .34 \\
2. School principal asking for you & $27 \%$ & .29 \\
3. No one arrived to party & $24 \%$ & .35 \\
4. School project, students giggling & $52 \%$ & .43 \\
5. Friend's parents annoyed & $14 \%$ & .39 \\
6. Playing game, students laughing & $37 \%$ & .67 \\
\hline
\end{tabular}

SASSY $=$ Self-report of Ambiguous Social Situations for Youth. 
Table 4

Descriptive correlations between age, SASSY, and other self-reports

\begin{tabular}{lccc}
\hline Variables & $\begin{array}{c}\text { SASSY-C } \\
\text { Total }\end{array}$ & $\begin{array}{c}\text { SASSY-C Factor } \\
\mathbf{1}(\mathbf{B} / \mathbf{A})\end{array}$ & $\begin{array}{c}\text { SASSY-C } \\
\text { Factor 2 (SR) }\end{array}$ \\
\hline SASSY Full Scale & --- & & \\
\hline SASSY Factor 1 (Blame/Accusation) & $.82^{*}$ & --- & \\
\hline SASSY Factor 2 (Peer Rejection) & $.87^{*}$ & $.43^{*}$ & --- \\
\hline Age & $.20^{*}$ & .12 & $.22^{*}$ \\
\hline MASC Total Score & $.25^{*}$ & $.17^{*}$ & $.25^{*}$ \\
\hline MASC Social Anxiety & $.36^{*}$ & .21 & $.39^{*}$ \\
\hline MASC Separation/Panic & .07 & .04 & .08 \\
\hline MASC Harm Avoidance & .04 & .02 & .05 \\
\hline MASC Physical Symptoms & $.19^{*}$ & .15 & $.17^{*}$ \\
\hline MFQ & .29 & .20 & .29 \\
\hline NASSQ Anxiety & $.38^{*}$ & $.28^{*}$ & $.35^{*}$ \\
\hline NASSQ Depression & $.34^{*}$ & $.25^{*}$ & $.27^{*}$ \\
\hline NASSQ Negative Affect & & & \\
\hline
\end{tabular}

Significant using a cutoff of $* p<.0018$.

B/A = Blame/Accusation; SR = Social Rejection; SASSY = Self-report of Ambiguous Social Situations for Youth; MASC =Multidimensional Anxiety Scale for Children; MFQ = Mood and Feelings Questionnaire; NASSQ = Negative Affectivity Self-Statement Questionnaire. 